\title{
Anemia and its associated factors among school-age children living in different climatic zones of Arba Minch Zuria District, Southern Ethiopia
}

Eshetu Zerihun Tariku ${ }^{* *}$ (D, Getaneh Alemu Abebe², Zeleke Aschalew Melketsedik, Befikadu Tariku Gutema', Nega Degefa Megersa ${ }^{3}$, Muluken Bekele Sorrie', Feleke Gebremeskel Weldehawariat ${ }^{1}$ and Eskeziyaw Agedew Getahun'

\begin{abstract}
Background: Anemia, defined as a low blood hemoglobin concentration, has been shown to be a major public health concern in low-income countries like Ethiopia. School-age children are the most vulnerable population groups for anemia. The aim of this study was to assess the prevalence of anemia, with consideration of altitudinal variations, and to identify factors associated with anemia among school-age children.

Methods: A community-based cross-sectional study was conducted from April to May 2017 among randomly selected 391 school-age children (6 to 14 years) in Arba Minch Health and Demographic Surveillance Site, Southern Ethiopia. Hemoglobin concentration was measured on the spot using portable hemoglobinometer (HemoCue $\mathrm{Hb}$ 201). The hemoglobin cut off values, adjusted for child age and altitude, were used to define anemia. Stool microscopic examination was done for investigation of intestinal parasites. A binary logistic regression model was used to assess the possible association of independent and outcome variables.

Results: The overall prevalence of anemia was 37.3\% (146); (95\% Cl: 32.5, 42.2). Among those who were anemic, 110 (28.1\%) and 35 (9\%) had mild (Hb 11-11.4 g/dl for children age from 6 to 11 years and 11-11.9 g/dl for children age from 12 to 14 years) and moderate $(\mathrm{Hb} 8-10.9 \mathrm{~g} / \mathrm{dl})$ anemia respectively. A single case of severe $(\mathrm{Hb}<8 \mathrm{~g} / \mathrm{dl})$ anemia was identified. Fifty-seven (46.3\%) of children living in an altitude $\geq 2500 \mathrm{~m}$ above sea level were anemic. Anemia was higher among children who were positive for intestinal parasitic infections ( $A O R=3.30,95 \% \mathrm{Cl}: 2.04,5$. 35 ) and children not-enrolled to schools $(\mathrm{AOR}=2.05,95 \% \mathrm{Cl}: 1.26,3.32)$. Anemia was less common among children who had no habit of eating vegetables in the last week prior to the survey ( $\mathrm{AOR}=0.35,95 \% \mathrm{Cl}: 0.14,0.84$ ).
\end{abstract}

Conclusions: More than one-third of school-age children were suffering from anemia. Intestinal parasitic infections and school non-enrollment were among the major factors associated with anemia among school-age children in the study area. Interventions, focusing on identified contributing factors need to be implemented by integrating with other school or community-based health programs.

Keywords: Anemia, School-age children, Altitude, Ethiopia

\footnotetext{
* Correspondence: eshetamu@gmail.com; eshetu.zerihun@amu.edu.et

1Department of Public Health, Arba Minch University, Arba Minch, Ethiopia

Full list of author information is available at the end of the article
}

(c) The Author(s). 2019 Open Access This article is distributed under the terms of the Creative Commons Attribution 4.0 International License (http://creativecommons.org/licenses/by/4.0/), which permits unrestricted use, distribution, and reproduction in any medium, provided you give appropriate credit to the original author(s) and the source, provide a link to the Creative Commons license, and indicate if changes were made. The Creative Commons Public Domain Dedication waiver (http://creativecommons.org/publicdomain/zero/1.0/) applies to the data made available in this article, unless otherwise stated. 


\section{Background}

Under-nutrition is one of the reasons behind high child mortality rates in developing countries. More than ten million children die each year, most from preventable causes and almost all in poor countries [1]. In Ethiopia, School-Age Children (SAC) are affected by a wide range of health and nutrition-related problems that constraint their ability to thrive and benefit from education [2]. Severe malnutrition is reported as the first leading cause of death among children aged 5 to 14 years old [3].

Anemia, defined as a low blood hemoglobin concentration, has been shown to be a public health problem that affects low-, middle- and high-income countries [4]. More than $40 \%$ SAC in developing countries are suffering from anemia and it is considered a severe public health problem. Sub-Saharan African countries shared a greater burden of the problem [5-7].

Based on pocket studies conducted in different parts of Ethiopia, the prevalence of anemia among SAC ranges from 23 to $38 \%$ [8-10]; while, the national level prevalence is not well documented.

Anemia has significant adverse health consequences, as well as adverse impacts on social and economic development [4]. It affects growth and energy levels adversely (5). It can also lead to reduced muscle function and work capacity; decreased school performance and increased school absenteeism in SAC [11, 12].

Anemia may result from a number of causes, with the most significant contributor being an iron deficiency (50\%) [13]. Hookworms, which feed on their host's blood and cause bleeding of the small intestine as well, are contributors of anemia. Recent studies have shown a marked increase in the prevalence of anemia caused by hookworm infection at age 5 to 14 years, particularly in tropical regions where hookworm prevalence is high $[4,5,14]$. Although iron-deficiency is the most common etiology of anemia globally, causes of anemia widely vary by geography, age group, and sex [14].

At elevations above $1000 \mathrm{~m}$, hemoglobin concentration increases as an adaptive response to the lower partial pressure of oxygen and reduced oxygen saturation of blood. Therefore, the altitude of residence site of healthy individuals is critical for the definition of anemia. Hence, the altitude, along with other variables, should be taken into account while interpreting hemoglobin values in population-based surveys [15]. However, most of the previous studies were describing the burden of anemia without considering the relationship between altitude and hemoglobin concentration. Many studies were also institution based and might be subjected to unobserved confounding factors.

Moreover, for effective treatment and prevention of nutritional problems, local investigation of the problems has paramount importance, taking into account the prevalence and specific risk factors in a given setting and population group [15]. The aims of the present study were, therefore, to assess the prevalence of anemia, with consideration of altitudinal variations, and to identify factors associated with anemia among SAC.

\section{Methods}

\section{Study design and setting}

A community-based cross-sectional study was conducted from April to May 2017 among SAC (6 to 14 years old) in Arba Minch Health and Demographic Surveillance Site (AM-HDSS), Arba Minch Zuria district, Southern Ethiopia. Arba Minch Zuria district has a total of 31 kebeles, among which 9 kebeles are included as the site for AM-HDSS. These nine kebeles, which are assumed to be the representative of all 31 kebeles in the district, were selected by stratifying based on their climatic zone (all the three different climatic zones: high land, midland and lowland, are included) and, in addition, one semi-urban kebele was also included. The HDSS has been running by Arba Minch University, Demographic and Health Research Center. The altitude of nine kebeles ranges from 1128 to 2866 above sea level. According to the HDSS report of January 2016, a total of 74, 157 individuals live in the surveillance site, of whom 20,062 (27.1\%) were aged between 6 and 14 years.

\section{Sample size and sampling technique}

The sample size was estimated using single population proportion formula through assumptions of the prevalence of anemia among SAC in Jimma, which was 37.6\% [16] at 95\% confidence level (CI), 5\% margin of error and adding $10 \%$ for non-responses. Finally, the study recruited a total of 397 children. All children aged 6 to 14 years old living in the nine kebeles of AM-HDSS were included as a source population. To select the study participants, AM-HDSS database, which contains the list of all individuals in the kebeles with their date of birth, individual and household identification, was used as a sampling frame. Then, considering the number of children living in each kebele, study participants were proportionally allocated. Study participants were selected following a simple random sampling technique using Stata version 14 software.

\section{Data collection methods}

Data were collected using structured, pretested Amharic version questionnaires. The study instruments included two sets of structured questionnaires. One was administered for children, and another for their family (children guardian preferably the mother). Data on family wealth, as a measure of economic status, was collected by asking ownership of selected assets that are common in the local area based on Ethiopian Demographic and Health 
Survey (EDHS) 2016 wealth index variables [17]. The household food insecurity level was measured using Household Food Insecurity Access Scale (HFIAS), which is a structured, standardized and validated tool that developed by Food and Nutrition Technical Assistance Project (FANTA) [18]. The child dietary intake pattern, for assessing the child dietary diversity, was measured by a qualitative recall of all foods consumed by each child during the previous $24 \mathrm{~h}$ based on Food and Agriculture Organization (FAO) Guideline. In addition, to assess the usual nutrient intake of the child, the frequency of consumption of certain nutrients 1 week prior to the survey was recorded [19]. Altitude, where each child resides, was measured to describe the malaria transmission pattern in the study area and to aid in the adjustment of the hemoglobin concentration of the child.

Weights of children were measured to the nearest 0.1 $\mathrm{kg}$ using calibrated portable electronic digital scale (Seca, Germany model) and heights were measured to the nearest $0.1 \mathrm{~cm}$ using a portable height-measuring board with a sliding head bar following standard anthropometric techniques [20].

\section{Hemoglobin measurement}

Trained medical laboratory technicians collect capillary blood samples in order to measure hemoglobin concentration of each child on the spot using portable hemoglobinometer (HemoCue $\mathrm{Hb}$ 201) following standard protocols as explained elsewhere [8].

\section{Stool examination}

Stool examination for microscopic detection of intestinal parasites was also conducted following standard protocol as explained elsewhere [21]. Detail of stool examination and findings are available in our previous publication [22].

\section{Data quality control}

A questionnaire was prepared in English and translated into Amharic language and again translated back to English. It was pretested by recruiting 20 children and their guardians in one of HDSS kebeles on households which were not selected for actual data collection. Data collectors were given 2 days of intensive training on the method of identifying the household, anthropometric measurements, blood and stool sample collection and examination, ethical issues and the purpose of the study. Hemoglobin measurement and stool microscopic examination were done following standard protocols. Investigators were supervising all aspects of data collection throughout the data collection period.

\section{Data analysis}

Data were entered using Epi Data version 3.1. For further analysis, the data was exported to Statistical Package for
Social Science (SPSS) version 22 software. Descriptive analysis was indicated using numerical summary measures. Households who experienced none of the food insecurity (access) conditions or just experiences worry, but rarely in the past 4 weeks were labeled as 'food secured, while the remaining were labeled as food insecure [18]. To calculate the child dietary diversity score, certain food groups were aggregated and the mean score was used to classify child food intake as adequate or not [19].

The blood hemoglobin cutoff values were adjusted for altitude before determining the children either as anemic or not. The adjustment was made based on the application of formula: $\mathrm{Hb}$ adjustment $=-0.32 \times$ (altitude in meters $\times .0033)+0.22 \times(\text { altitude in meters } \times .0033)^{2}$. Then, the adjustment was subtracted from the measured hemoglobin concentration at the relevant altitude to get the sea-level value [23-25]. The hemoglobin concentration cutoff points for anemia were $11.5 \mathrm{~g} / \mathrm{dl}$ for children age from 6 to 11 years and $12 \mathrm{~g} / \mathrm{dl}$ for children age from 12 to 14 years. Those children with hemoglobin concentration below $8 \mathrm{~g} / \mathrm{dl}$ and between 8 and $10.9 \mathrm{~g} / \mathrm{dl}$ were further classified as severe and moderate anemia, respectively. The remaining anemic children with hemoglobin concentration between 11 and $11.4 \mathrm{~g} / \mathrm{dl}$ (for children age from 6 to 11 years) and $11-11.9 \mathrm{~g} / \mathrm{dl}$ (for children age from 12 to 14 years) were categorized as mild anemia [26].

The wealth index was constructed via Principal Component Analysis (PCA) method [27]. For anthropometric data analysis, standard deviation (Z-scores) scores were obtained by the World Health Organization (WHO) Anthro Plus software. Children whose Height for Age z-score (HAZ) and BMI for Age z-score (BAZ) above-2SD scores were considered as well-nourished and those below -2SD scores as being malnourished (stunted and thin respectively) [28, 29]. Malaria transmission pattern in the study area was described based on the difference in altitude: malaria-free highland areas (above $2500 \mathrm{~m}$ altitude); highland fringe areas between 1500 and $2500 \mathrm{~m}$ affected by frequent epidemics; and lowland areas below $1500 \mathrm{~m}$ with seasonal patterns of transmission [30].

All covariates that were significant at $p$-value $<0.25$ in bivariate analysis were considered for multivariable analysis to control possible confounders. To measure the strength of association between dependent and independent variables, Adjusted Odds Ratio (AOR) with 95\% Confidence interval (CI) was calculated. Finally, the level of statistical significance was declared at $p$-value $<0.05$. The fitness of the model was tested by Hosmer- Lemeshow goodness of fit test and the test revealed a $p$-value of 0.820 showing the model was fit. 


\section{Results}

Socio-demographic and economic characteristics of study participants

A total of 391 SAC with their mothers/caregivers were participated in making a response rate of $98.5 \%$. More than half of respondents, $(65.0 \%)$ were in the age group of $6-11$ years. The mean \pm SD of the age of children was $10.1 \pm 2.6$ years while that of parents/ caregivers was 37 \pm 8.7 years. Nearly half $(50.1 \%)$ of the participating children were male and 223 (57.0\%) were enrolled in school. Concerning the educational status of parents, 257 (65.7\%) of mothers/ caregivers, had no formal education while $132(33.8 \%)$ of fathers had formal education. A total of 370 (94.6\%) mothers were housewives while 133 (34\%) of the fathers were farmers.

In the study area, 130 (33.25\%) of households were in the poor wealth terciles; 206 (52.7\%) of households were food insecure and 159 (40.7\%) of surveyed households were residing in kebeles with an altitude $<1500 \mathrm{~m}$ where seasonal transmission of malaria is common (Table 1).

\section{Anthropometric status, dietary and clinical characteristics of study participants}

Out of all children included in this study, 163 (41.9\%) were with height for age $<-2 \mathrm{Z}$ score and 31 (8.0\%) were with BMI for age $<-2 \mathrm{Z}$ score. The detail on the anthropometric

Table 1 Distribution of socio-demographic and economic characteristics of school age children with and without anemia $(n=391)$, Arba Minch Zuria District, Southern Ethiopia, April to May 2017

\begin{tabular}{|c|c|c|c|c|c|}
\hline \multirow[t]{2}{*}{ Variables } & \multirow[t]{2}{*}{ Categories } & \multicolumn{2}{|l|}{ Anemic } & \multirow[t]{2}{*}{ COR $(95 \% \mathrm{Cl})$} & \multirow[t]{2}{*}{$p$-value } \\
\hline & & Yes (\%) & No (\%) & & \\
\hline \multirow[t]{2}{*}{ Age of child (in years) } & $6-11$ & $100(39.4)$ & $154(60.6)$ & $1.26(0.83-1.98)$ & 0.259 \\
\hline & $12-14$ & $46(33.6)$ & $91(66.4)$ & 1 & \\
\hline \multirow[t]{2}{*}{ Child sex } & Male & $72(36.7)$ & $124(63.3)$ & 1 & \\
\hline & Female & $74(37.9)$ & $121(62.1)$ & $1.05(0.70-1.59)$ & 0.804 \\
\hline \multirow[t]{2}{*}{ School Enrolment } & Enrolled & $69(30.9)$ & $154(69.1)$ & 1 & \\
\hline & Non enrolled & $77(45.8)$ & $91(54.2)$ & $1.89(1.25-2.86)$ & $0.003^{*}$ \\
\hline \multirow[t]{3}{*}{ Age of parent/ care giver } & $18-35$ & $68(35.4)$ & $124(64.6)$ & 1 & \\
\hline & $36-45$ & $58(39.7)$ & $88(60.3)$ & $1.20(0.77-1.87)$ & 0.417 \\
\hline & $>45$ & $20(37.7)$ & $33(62.8)$ & $1.11(0.59-2.07)$ & 0.755 \\
\hline \multirow[t]{2}{*}{ Sex of parent/ care giver } & Male & $54(45.8)$ & $64(54.2)$ & 1 & \\
\hline & Female & $92(33.7)$ & $181(66.3)$ & $0.60(0.39-0.94)$ & $0.024^{*}$ \\
\hline \multirow[t]{2}{*}{ Educational status of mother } & $\begin{array}{l}\text { No formal education/unable } \\
\text { to read and write }\end{array}$ & $114(38.6)$ & $181(61.4)$ & $1.26(0.78-2.05)$ & 0.351 \\
\hline & Formal education & $32(33.3)$ & $64(66.7)$ & 1 & \\
\hline \multirow[t]{2}{*}{ Educational status of father } & No formal education & $103(39.8)$ & $156(60.2)$ & $1.37(0.88-2.12)$ & $0.165^{*}$ \\
\hline & Formal education & $43(32.6)$ & $89(67.4)$ & 1 & \\
\hline \multirow[t]{2}{*}{ Occupation of mother/ care giver } & Housewife & $141(38.1)$ & $229(61.9)$ & $1.97(0.71-5.50)$ & $0.195^{*}$ \\
\hline & Working & $5(23.8)$ & $16(76.2)$ & 1 & \\
\hline \multirow[t]{2}{*}{ Occupation of father } & Government employee & $7(58.3)$ & $5(41.7)$ & $2.42(0.75-7.76)$ & $0.138^{*}$ \\
\hline & Private employee & $139(36.7)$ & $240(63.3)$ & 1 & \\
\hline \multirow[t]{2}{*}{ Family size (in number) } & $<4$ & $5(27.8)$ & $13(72.2)$ & 1 & \\
\hline & $>=4$ & $141(37.8)$ & $232(62.2)$ & $1.58(0.55-4.53)$ & 0.394 \\
\hline \multirow[t]{3}{*}{ Family wealth terciles } & Poor & $53(40.8)$ & $77(59.2)$ & $1.39(0.84-2.31)$ & $0.199 *$ \\
\hline & Medium & $50(38.2)$ & $81(61.8)$ & $1.25(0.75-2.08)$ & 0.391 \\
\hline & Rich & $43(33.1)$ & $87(66.9)$ & 1 & \\
\hline \multirow[t]{2}{*}{ Household food security status } & Food secured & $68(36.8)$ & $117(63.2)$ & 1 & \\
\hline & Food insecured & $78(37.9)$ & $128(62.1)$ & $1.05(0.70-1.58)$ & 0.821 \\
\hline \multirow[t]{3}{*}{ Altitude in meter (based on malaria transmission) } & $<1500$ & $49(30.8)$ & $110(69.2)$ & $0.52(0.32-0.84)$ & $0.008^{*}$ \\
\hline & $1500-2500$ & $40(36.7)$ & $69(63.3)$ & $0.67(0.40-1.14)$ & $0.138^{*}$ \\
\hline & Malaria free $(\geq 2500)$ & $57(46.3)$ & $66(53.7)$ & 1 & \\
\hline
\end{tabular}


status of the child is found in our previously published article [31]. The stool samples were collected from 391 children among which 182 (46.5\%) of children were positive for intestinal parasites and the remaining 209 (53.5) were negative. Ascaris lumbricoides (14.2\%) and hookworms (14.1\%) being the predominant species. Only 16 (4.1\%) of children reported the presence of illness 2 weeks prior to the survey. Nearly all children, 364 (93.1\%) had no habit of consumption of meat or meat products 1 week prior to the survey. More than half of children, 238 (60.9\%), had a Dietary Diversity Score (DDS) of $\geq 4$ food groups (Table 2).

\section{Prevalence of anemia among study participants}

Before the adjustment of children hemoglobin concentration for altitude, the mean \pm SD hemoglobin level of study participant was $13.1 \pm 1.8$. After adjustment, the mean \pm SD hemoglobin level of study participant was

Table 2 Distribution of child health, dieting habit and environmental characteristics of school age children with and without anemia $(n=391)$, Arba Minch Zuria District, Southern Ethiopia, April to May 2017

\begin{tabular}{|c|c|c|c|c|c|}
\hline \multirow[t]{2}{*}{ Variables } & \multirow[t]{2}{*}{ Category } & \multicolumn{2}{|l|}{ Anemic } & \multirow[t]{2}{*}{ COR $(95 \% \mathrm{Cl})$} & \multirow[t]{2}{*}{$p$-value } \\
\hline & & Yes (\%) & No (\%) & & \\
\hline \multirow{2}{*}{$\begin{array}{l}\text { Presence of illness in the last two weeks prior } \\
\text { to the survey }\end{array}$} & Yes & $2(12.5)$ & $14(87.5)$ & $0.23(0.05-1.02)$ & $0.054^{*}$ \\
\hline & No & $144(38.4)$ & 231 (61.6) & 1 & \\
\hline \multirow[t]{2}{*}{ Current IP infection } & Positive & $87(47.8)$ & $95(52.2)$ & $2.33(1.53-3.54)$ & $0.000^{*}$ \\
\hline & Negative & $59(28.2)$ & $150(71.8)$ & 1 & \\
\hline \multirow[t]{2}{*}{$H A Z<-2$} & Yes & $69(42.3)$ & $94(57.7)$ & $1.42(0.94-2.15)$ & $0.097^{*}$ \\
\hline & No & $77(34.1)$ & 149 (65.9) & 1 & \\
\hline \multirow[t]{2}{*}{$B A Z<-2$} & Yes & $13(41.9)$ & $18(58.1)$ & $1.22(0.58-2.57)$ & 0.598 \\
\hline & No & $133(37.2)$ & $225(62.8)$ & 1 & \\
\hline \multirow{3}{*}{$\begin{array}{l}\text { Number of days the child eat fruit in the last } \\
\text { week prior to the survey }\end{array}$} & Do not eat fruits & $94(44.1)$ & $119(55.9)$ & $1.81(1.01-3.22)$ & $0.046^{*}$ \\
\hline & $<=3$ days & $31(28.4)$ & 78 (71.6) & $0.91(0.47-1.76)$ & 0.776 \\
\hline & $>3$ days & $21(30.4)$ & $48(69.6)$ & 1 & \\
\hline \multirow{2}{*}{$\begin{array}{l}\text { Number of serving of fruit the child eat on one } \\
\text { of those days }\end{array}$} & $<3$ servings & $44(28.0)$ & $113(72.0)$ & $0.63(0.25-1.63)$ & 0.344 \\
\hline & $>=3$ servings & $8(38.1)$ & $13(61.9)$ & 1 & \\
\hline \multirow{3}{*}{$\begin{array}{l}\text { Number of days the child eat vegetables in the } \\
\text { last week prior to the survey }\end{array}$} & Do not eat vegetables & $13(24.5)$ & $40(75.5)$ & $0.44(0.22-0.86)$ & $0.017^{*}$ \\
\hline & $<=3$ days & $41(33.3)$ & $82(66.7)$ & $0.67(0.42-1.06)$ & $0.088^{*}$ \\
\hline & $>3$ days & $92(42.8)$ & $123(57.2)$ & 1 & \\
\hline \multirow{2}{*}{$\begin{array}{l}\text { Number of serving of vegetables the child eat on } \\
\text { one of those days }\end{array}$} & $<3$ servings & $127(39.8)$ & $192(60.2)$ & $1.43(0.53-3.87)$ & 0.477 \\
\hline & $>=3$ servings & $6(31.6)$ & $13(68.4)$ & 1 & \\
\hline \multirow{3}{*}{$\begin{array}{l}\text { Number of days the child eat meat/meat products } \\
\text { in the last week prior to the survey }\end{array}$} & Do not eat meat/MPs & $136(37.4)$ & $228(62.6)$ & $0.60(0.04-9.61)$ & 0.716 \\
\hline & $<=3$ days & $9(36.0)$ & $16(64.0)$ & $0.56(0.03-10.12)$ & 0.696 \\
\hline & $>3$ days & $1(50.0)$ & $1(50.0)$ & 1 & \\
\hline \multirow[t]{2}{*}{ Child DDS } & $<4$ food groups & $65(42.5)$ & $88(57.5)$ & $1.43(0.94-2.17)$ & $0.092^{*}$ \\
\hline & $>=4$ food groups & $81(34.0)$ & $157(66.0)$ & 1 & \\
\hline \multirow[t]{2}{*}{ Latrine availability at home } & Yes & $138(36.9)$ & $236(63.1)$ & 1 & \\
\hline & No & $8(47.1)$ & $9(52.9)$ & $1.52(0.57-4.03)$ & 0.400 \\
\hline \multirow[t]{2}{*}{ Source of drinking water } & Safe (pipe, protected well or spring) & $127(37.5)$ & $212(62.5)$ & 1 & \\
\hline & Unsafe (river, unprotected well or spring) & $19(36.5)$ & $33(63.5)$ & $0.96(0.52-1.76)$ & 0.898 \\
\hline \multirow[t]{2}{*}{ Waste disposal system } & Appropriate (burning, pit, garbage can) & $111(35.5)$ & $202(64.5)$ & 1 & \\
\hline & Inappropriate (open field/no disposal system) & $35(44.9)$ & $43(55.1)$ & $1.48(0.90-2.45)$ & $0.126^{*}$ \\
\hline \multirow[t]{2}{*}{ Ever sleeps under bed net } & Yes & $52(34.0)$ & $101(66.0)$ & 1 & \\
\hline & No & $94(39.5)$ & $144(60.5)$ & $1.27(0.83-1.94)$ & 0.272 \\
\hline \multirow[t]{2}{*}{ Ever received health or nutrition related information } & Yes & $61(33.3)$ & $122(66.7)$ & 1 & \\
\hline & No & $85(40.9)$ & $123(59.1)$ & $1.38(0.91-2.09)$ & $0.125^{*}$ \\
\hline
\end{tabular}


$12.3 \pm 1.8$. The overall prevalence of anemia among SAC was $37.3 \%$ (146); (95\% CI: 32.5, 42.2). Among those who were anemic, 110 (28.1\%) (95\% CI: 23.8, 33.0) had mild form of anemia, 35 (9\%) (95\% CI: 6.1, 11.8) moderate form of anemia, and a single case of severe anemia (0.3\%) (95\% CI: 0.0, 0.8) was identified. The prevalence of anemia was 57 (46.3\%), 40 (36.7\%) and $49(30.8 \%)$ in an altitude ranges of $\geq 2500 \mathrm{~m}$, between 1500 and 2500 $\mathrm{m}$ and $<1500 \mathrm{~m}$ respectively, even though, the difference is not statistically significant when adjusted for other covariates.

\section{Factors associated with anemia among study participants}

The present study identified major modifiable associated factors for anemia. Children who were positive for intestinal parasitic infections were 3.3 times more likely to be anemic than those negative for intestinal parasitic infection $(\mathrm{AOR}=3.30,95 \% \mathrm{CI}: 2.04,5.35)$. The likelihood of anemia was also higher among children not-enrolled in schools $(\mathrm{AOR}=2.05,95 \% \mathrm{CI}: 1.26,3.32)$ than those children who were enrolled. When compared with children who had the habit of eating vegetables for more than 3 days in 1 week prior to the survey, anemia was less common among children who had no habit of eating vegetables in 1 week prior to the survey $(\mathrm{AOR}=0.35$, 95\%CI: 0.14, 0.84) (Table 3).

\section{Discussion}

The present study revealed that about $37.3 \%$ of SAC were anemic. This finding is in agreement with the prevalence of anemia reported by a study from Jimma, Ethiopia (37.6\%) [16]. It also concurs with a report from India (37.5\%); even though the method used to diagnose anemia was based on clinical examinations [32].

The prevalence of anemia among SAC in the present study is higher than research finding from Somali and Kersa Ethiopia where the prevalence of anemia was 23.7 and $27.1 \%$ respectively $[8,10]$. The higher prevalence of anemia in our study might be attributed to the difference in the study period, the hemoglobin cut-off value used to diagnose anemia (we considered hemoglobin adjustment for altitude), and a relatively higher proportion of children affected by intestinal parasites; which is one of the contributing factors for the development of anemia. In this study, the overall prevalence of anemia, without the adjustment, was $22.5 \%$. This is an indication that the prevalence of anemia is underestimated if the hemoglobin concentration cut-off values are not adjusted for important variables like altitude. As expected, the prevalence of anemia reported by the present study is much higher than the prevalence reported elsewhere in developed countries like the United States, Colombia, and Mexico; which was below $12.0 \%$ [32]. The variation could probably attribute to the difference in socio-economic and demographic characteristics of study participants.

Infection and malnutrition have a bidirectional relationship. Chronic worm infections often make children malnourished, anemic and vulnerable to illnesses. The present study identified a statistically significant association between intestinal parasitic infection and child anemia. The odds of developing anemia were 3.3 times more common among children who were positive for intestinal parasitic infections than those who were tested negative. This is in agreement with evidence from the study conducted in Somali, Ethiopia [8]. This might be due to the fact that hookworms, which feed on their host's blood and cause bleeding of the small intestine as well, are among the predominant parasites detected.

Children who had no habit of eating vegetables in a week prior to the survey were $65 \%$ less likely to be anemic compared to children who had the habit of eating vegetables for more than 3 days in a week. This could be explained by vegetables are among the nonheam dietary iron sources which have poor bioavailability, and their absorption can be influenced by different factors. Thus, unless the consumption of such dietary sources are supplemented with optimal nutrition education interventions, addressing the number of servings per day and about the type of foods that will potentially inhibit its absorption, the habit of consumption of vegetables alone cannot be a guarantee for reducing the risk of anemia [33, 34]. However, since the majority of resource-poor countries are using non-haem iron as the main source of dietary iron, the consumption of vegetables should be encouraged as it is among the good dietary groups for the population predominantly based on non-heme iron [35].

In this study, anemia was 2 times more common among children not-enrolled in schools than those children who were enrolled. This could be explained by the probability that children who were not enrolled in schools, in most rural areas, are widely engaged in activities that let them stay outside their home. Consequently, they may not have access to sufficient care and support from their families which could contribute to the depletion of their nutritional status [36].

Although the prevalence of anemia was higher (46.3\%) among SAC residing in higher altitudes, the difference was not statistically significant ( $p$-value: 0.552 ). Similarly, the present study did not find a statistically significant association between the child anthropometric status and the presence of anemia. The relatively low prevalence of thinness $(8.0 \%)$ could be one reason for the absence of a statistically significant association. However, the multivariable logistic regression analysis showed that anemia was more common (42.3\%) among stunted children $(\mathrm{HAZ}<-2)$ than their counterparts, non-stunted children (34.1\%). 
Table 3 Multivariable logistic regression analysis showing factors associated with anemia among school aged children ( $n=391$ ), Arba Minch Zuria District, Southern Ethiopia, April to May 2017

\begin{tabular}{|c|c|c|c|c|c|}
\hline \multirow[t]{2}{*}{ Variables } & \multirow[t]{2}{*}{ Categories } & \multicolumn{2}{|l|}{ Anemic } & \multirow[t]{2}{*}{ AOR $(95 \% \mathrm{Cl})$} & \multirow[t]{2}{*}{$p$-value } \\
\hline & & Yes (\%) & No (\%) & & \\
\hline \multirow[t]{2}{*}{ School Enrolment } & Enrolled & $69(30.9)$ & $154(69.1)$ & 1 & \\
\hline & Non enrolled & $77(45.8)$ & $91(54.2)$ & $2.05(1.26-3.32)$ & $0.004^{*}$ \\
\hline \multirow[t]{2}{*}{ Sex of parent/ care giver } & Male & $54(45.8)$ & $64(54.2)$ & 1 & \\
\hline & Female & $92(33.7)$ & $181(66.3)$ & $0.65(0.36-1.14)$ & 0.133 \\
\hline \multirow[t]{2}{*}{ Educational status of father } & No formal education & $103(39.8)$ & $156(60.2)$ & $0.87(0.47-1.63)$ & 0.666 \\
\hline & Formal education & $43(32.6)$ & $89(67.4)$ & 1 & \\
\hline \multirow[t]{2}{*}{ Occupation of mother/ care giver } & Housewife & $141(38.1)$ & $229(61.9)$ & $2.09(0.64-6.76)$ & 0.220 \\
\hline & Working & $5(23.8)$ & $16(76.2)$ & 1 & \\
\hline \multirow[t]{2}{*}{ Occupation of father } & Government employee & $7(58.3)$ & $5(41.7)$ & $3.41(0.84-13.96)$ & 0.088 \\
\hline & Private employee & $139(36.7)$ & $240(63.3)$ & 1 & \\
\hline \multirow[t]{3}{*}{ Family wealth terciles } & Poor & $53(40.8)$ & $77(59.2)$ & $0.63(0.23-1.73)$ & 0.369 \\
\hline & Medium & $50(38.2)$ & $81(61.8)$ & $0.70(0.29-1.69)$ & 0.422 \\
\hline & Rich & $43(33.1)$ & $87(66.9)$ & 1 & \\
\hline \multirow[t]{3}{*}{ Altitude in Meter (based on malaria transmission) } & $<1500$ & $49(30.8)$ & $110(69.2)$ & $0.66(0.17-2.56)$ & 0.546 \\
\hline & $1500-2500$ & $40(36.7)$ & $69(63.3)$ & $0.77(0.33-1.81)$ & 0.552 \\
\hline & Malaria free (> 2500) & $57(46.3)$ & $66(53.7)$ & 1 & \\
\hline \multirow{2}{*}{$\begin{array}{l}\text { Presence of illness in the last two weeks prior } \\
\text { to the survey }\end{array}$} & Yes & $2(12.5)$ & $14(87.5)$ & $0.30(0.06-1.57)$ & 0.153 \\
\hline & No & $144(38.4)$ & $231(61.6)$ & 1 & \\
\hline \multirow[t]{2}{*}{ Current IP infection } & Positive & $87(47.8)$ & $95(52.2)$ & $3.30(2.04-5.35)$ & $0.000^{*}$ \\
\hline & Negative & $59(28.2)$ & $150(71.8)$ & & \\
\hline \multirow[t]{2}{*}{$H A Z<-2 Z$ score } & Yes & $69(42.3)$ & $94(57.7)$ & $1.22(0.74-2.03)$ & 0.443 \\
\hline & No & $77(34.1)$ & $149(65.9)$ & & \\
\hline \multirow{3}{*}{$\begin{array}{l}\text { Number of days the child eat fruit in the last week } \\
\text { prior to the survey }\end{array}$} & Do not eat fruits & $94(44.1)$ & $119(55.9)$ & $1.70(0.57-5.06)$ & 0.339 \\
\hline & $<=3$ days & $31(28.4)$ & $78(71.6)$ & $1.08(0.51-2.31)$ & 0.842 \\
\hline & $>3$ days & $21(30.4)$ & $48(69.6)$ & 1 & \\
\hline \multirow{3}{*}{$\begin{array}{l}\text { Number of days the child eat vegetables in the } \\
\text { last week prior to the survey }\end{array}$} & Do not eat vegetables & $13(24.5)$ & $40(75.5)$ & $0.35(0.14-0.84)$ & $0.019^{*}$ \\
\hline & $<=3$ days & $41(33.3)$ & $82(66.7)$ & $0.83(0.43-1.63)$ & 0.597 \\
\hline & $>3$ days & $92(42.8)$ & $123(57.2)$ & 1 & \\
\hline \multirow[t]{2}{*}{ Child DDS } & $<4$ food groups & $65(42.5)$ & $88(57.5)$ & $1.27(0.66-2.44)$ & 0.473 \\
\hline & $>=4$ food groups & $81(34.0)$ & $157(66.0)$ & 1 & \\
\hline \multirow[t]{2}{*}{ Waste disposal system } & Appropriate (burning, pit, garbage can) & $111(35.5)$ & $202(64.5)$ & 1 & \\
\hline & Inappropriate (open field/no disposal system) & $35(44.9)$ & $43(55.1)$ & $0.56(0.22-1.42)$ & 0.222 \\
\hline \multirow[t]{2}{*}{ Ever received health or nutrition related information } & Yes & $61(33.3)$ & $122(66.7)$ & 1 & \\
\hline & No & $85(40.9)$ & $123(59.1)$ & $1.19(0.67-2.12)$ & 0.546 \\
\hline
\end{tabular}

AOR Adjusted Odds Ratio, Cl Confidence Interval; ${ }^{*}=p$-value $<0.05$

One of the strengths of this study is that it was community-based and can provide information about both enrolled and not-enrolled SAC. The study also tried to address multifactorial causes of anemia including investigation of the presence of intestinal parasitic infections. The application of standard criteria's (like hemoglobin adjustment for altitude difference) was also the strength of the present study. Recall bias is one of the limitations of this study since some of the questions (food security questions) asked respondents to remember the event during the last 4 weeks. This was minimized by probing the respondents about the event. The other limitation of this study is it couldn't tell us about a specific type of anemia since the detailed morphological investigation of red blood cells was not made. 


\section{Conclusions}

More than one-third of SAC was suffering from anemia. Intestinal parasitic infections and being not-enrolled in schools were found to be the major factors contributed to the development of anemia in the study area. The habit of consumption of vegetables within a week prior to the survey was also associated with anemia among SAC. Thus, interventions, focusing on identified contributing factors; need to be implemented by integrating with other school health programs to improve the nutritional status of SAC. Measures targeted at reducing the burden of intestinal parasitic infection should be strengthened to reduce the burden of anemia. Emphasis should also be given to improving children enrolment to schools. Nutrition education programs, mainly focusing on the consumption of dietary sources of iron, are beneficial to reduce the burden of anemia. In addition, further study to assess specific causes of anemia using detail morphological investigations is recommended.

\section{Abbreviations}

AM-HDSS: Arba Minch Health and Demographic Surveillance Site; SAC: School Age Children

\section{Acknowledgments}

We are very much great full to all study participants, data collectors, and Arba Minch Zuria district administrative offices for their valuable contribution to conduct this study. We also extend our gratitude to AM- HDSS office: for providing us the sampling frame and for their continuous support during data collection time. Last but not least, we are greatly indebted to the Ethiopian Public Health Institute (EPHI) for its material assistance.

\section{Funding}

Fund for data collection and laboratory analysis was obtained from Arba Minch University. No fund was obtained for designing of the study, statistical analysis of data, interpretation of data and writing of the report. The funding source has no role in the decision to submit the article for publication.

\section{Availability of data and materials}

The original data for this study is available from the corresponding author.

\section{Authors' contributions}

EZT conceived and designed the project. EZT, GAA, ZAM, and BTG analyzed and interpreted the data, and wrote the manuscript. EZT, GAA, ZAM, BTG, NDM, MBS, FGW and EAG critically revised the article for intellectual content, read and approved the final version of the manuscript.

\section{Ethics approval and consent to participate}

Ethical approval was obtained from the Institutional Ethics Review Board (IRB) of Arba Minch University with a project code of CMHS/5203/09. Individual informed written consent was obtained from the parents or legal guardians of the children included in this study. The respondents were assured of confidentiality. Children, who were positive for intestinal helminthes after laboratory investigations, were de-wormed after communicating with local health offices. In addition, a child with severe anemia was linked to the nearby health facility for further diagnosis and treatment.

\section{Consent for publication}

Not applicable.

\section{Competing interests}

The authors declare that they have no competing interests.

\section{Publisher's Note}

Springer Nature remains neutral with regard to jurisdictional claims in published maps and institutional affiliations.

\section{Author details}

'Department of Public Health, Arba Minch University, Arba Minch, Ethiopia. ${ }^{2}$ Department of Medical Laboratory Science, Bahir Dar University, Bahir Dar, Ethiopia. ${ }^{3}$ Department of Nursing, Arba Minch University, Arba Minch, Ethiopia.

Received: 15 November 2018 Accepted: 4 March 2019

Published online: 23 April 2019

\section{References}

1. Black RE, Morris SS, Bryce J. Where and why are 10 million children dying every year? Lancet. 2003;361(9376):2226-34

2. Situation Analysis on School Health and Nutrition in Ethiopia, Ministry of Education (MoE), 2008, Addis Ababa, Ethiopia.

3. Dedefo M, Zelalem D, Eskinder B, Assefa N, Ashenafi W, Baraki N, et al. Causes of death among children aged 5 to 14 years old from 2008 to 2013 in Kersa health and demographic surveillance system (Kersa HDSS), Ethiopia. PLoS One. 2016;11(6):e0151929.

4. World Health Organization (WHO). The global prevalence of anemia. Geneva; 2015.

5. United Nations Children's Fund/United Nations University/World Health Organization (WHO). Iron deficiency anaemia. Assessment, prevention and control. A guide for programme managers (WHO/NHD/01.3). Geneva; 2001. p. 15-31.

6. Benoist B, McLean E, Cogswell M, Egli I, Wojdyla D. Worldwide prevalence of anemia 1993-2005. Geneva: World Health Organization Global Database on Anemia; 2008. p. 7-13.

7. Tatala SR, Kihamia CM, Kyungu LH, Svanberg U. Risk factors for anemia in school children in Tanga Region, Tanzania. Tanzan J Health Res. 2008;10(4): 189-202.

8. Gutema B, Adissu W, Asress Y, Gedefaw L. Anemia and associated factors among school-age children in Filtu Town, Somali region, Southeast Ethiopia. BMC Hematology. 2014;14:13.

9. Das S, Addhya D, Chakrabarty F. Prevalence of thinness among 6-12 years rural children of Kharagpur. Antrocom Online J Anthropol. 2012;8(1):1973-2880.

10. Mesfin F, Berhane $Y$, Worku A. Anemia among primary school children in eastern Ethiopia. PLoS One. 2015;10(4):e0123615. https://doi.org/10.1371/ journal.pone.0123615.

11. Haas JD, Brownlie T. Iron deficiency and reduced work capacity: a critical review of the research to determine a causal relationship. J Nutr. 2001;131: 676S-88S

12. Sharp P. Minerals and trace elements. In: Geissler C, Powers H, editors. Human nutrition and dietetics, 11 edn. London: Churchill Livingstone; 2005. p. 241-4.

13. Nutritional anemia. tools for effective prevention and control. Geneva: World Health Organization; 2017. Licence: CC BY-NC-SA 3.0 IGO

14. Nicholas J., Jasrasaria R., Naghavi M., Sarah K., Nicole Johns N., Lozano R., Regan M.. A systematic analysis of global anemia burden from 1990 to 2010. 2014; 123 (5). Available at www.bloodjournal.org Accessed 27 Oct 2016.

15. Sullivan KM, Mei Z, Grummer-Strawn L, Parvanta I. Hemoglobin adjustments to define anemia. Trop Med Int Health. 2008;13(1):1267-71. https://doi.org/ 10.1111/j.1365-3156.2008.02143.x.

16. Assefa S, Mossie A, Hamza L. Prevalence and severity of anemia among school children in Jimma Town, Southwest Ethiopia. BMC Hematology. 2014;14:3.

17. Central Statistical Agency and ICF International. Ethiopia demographic and health survey Addis Ababa, Ethiopia and Calverton, Maryland, USA. 2016.

18. Coates J, Swindale A, Blinisky P. Household Food Insecurity Access Scale (HFIAS) for Measurement of Food Access: Indicator Guide VERSION 3. Washington, D.C.: Food and Nutrition Technical Assistance Project, Academy for Educational Development; 2007a.

19. Kennedy, G., Ballard, T. and Dop, M. C. Guidelines for measuring household and individual dietary diversity. Nutrition and consumer protection division, Food and Agriculture Organization of the United Nations; 2013.

20. National Health And Nutrition Examination Survey (NHANES). Anthropometry procedures manual. 2007. Available at http://www.cdc.gov/ nchs/about/major/nhanes/datalink.htm. Accessed 14 Jan 2017. 
21. Alemu G, Mama M. Intestinal helminth co-infection and associated factors among tuberculosis patients in Arba Minch, Ethiopia. BMC Infect Dis. 2017 17:16. https://doi.org/10.1186/s12879-12017-12195-12871.

22. Alemu G, Aschalew Z, Zerihun E. Burden of intestinal helminths and associated factors three years after initiation of mass drug administration in Arbaminch Zuria district, southern Ethiopia. BMC Infect Dis. 2018;18(1):435.

23. Communicable Disease Control (CDC). CDC criteria for anemia in children and child bearing aged women. Morb Mortal Wkly Rep 1989; 38, 400-404.

24. The International Nutritional Anemia Consultative Group (INACG). Adjusting hemoglobin values in program surveys. 2002.

25. Nutritional Anaemias. Report of a WHO Scientific Group, vol. 405. Geneva: World Health Organization. WHO Technical Report Series; 1968.

26. World Health Organization (WHO), Hemoglobin concentrations for the diagnosis of anemia and assessment of severity. Vitamin and Mineral Nutrition Information System. Geneva: World Health Organization (WHO/ $\mathrm{NMH/NHD/MNM/11.1)} 2011$.

27. Raya, R., Reyes, J. and Almoro, D. 10). Education Watch Toolkit A Resource Pack for EFA. Research and Monitoring: Module 5: The Wealth Index. AsiaSouth Pacific Education Watch. 2010; Available at http://www.aspbae.org.

28. World Health Organization. Physical status: the use and interpretation of anthropometry. Report of a WHO expert committee. World Health Organ Tech Rep Ser. 1995:854:1-452.

29. De Onis M, Onyango AW, Borghi E, Siyam A, Nishida C, Siekmann J. Development of a WHO growth reference for school-aged children and adolescents. Bull World Health Organ. 2007;85:660-7.

30. National Malaria Control Team, Ethiopian Public Health Institute, World Health Organization, Addis Ababa University and the INFORM Project. An epidemiological profile of malaria in Ethiopia. UK: A report prepared for the Federal Ministry of Health, Ethiopia, the Roll Back Malaria Partnership and the Department for International Development; 2014.

31. Tariku EZ, Abebe GA, Melketsedik ZA, Gutema BT. Prevalence and factors associated with stunting and thinness among school-age children in Arba Minch health and demographic surveillance site, Southern Ethiopia. PLoS One. 2018, e0206659;13(11). https://doi.org/10.1371/journal.pone.0206659.

32. Srivastava A, Mahmood S, Srivastava M, Shrotriya P, Kumar B. Nutritional status of school-age children - a scenario of urban slums in India. Arch Public Health. 2012:70:8

33. Ghose B, Yaya S. Fruit and vegetable consumption and anemia among adult non-pregnant women: Ghana demographic and health survey. PeerJ. 2018;6:e4414

34. Hurrell RF, Reddy M, Cook JD. Inhibition of non-haem iron absorption in man by polyphenolic-containing beverages. Br J Nutr. 1999; (4):289-95.

35. Syed S, Addo O, Cruz-Góngora V, Fayrouz A, Ashour S, Ziegler R, Suchdev S. Determinants of Anemia among school-aged children in Mexico, United States and Colombia. Nutrients. 2016;8:387.

36. De Hoop J, Friedman J, Kandpal E, Rosati F. Child schooling and child work in the presence of a partial education subsidy: The World Bank; 2017.

Ready to submit your research? Choose BMC and benefit from:

- fast, convenient online submission

- thorough peer review by experienced researchers in your field

- rapid publication on acceptance

- support for research data, including large and complex data types

- gold Open Access which fosters wider collaboration and increased citations

- maximum visibility for your research: over $100 \mathrm{M}$ website views per year

At $\mathrm{BMC}$, research is always in progress.

Learn more biomedcentral.com/submissions 